\title{
A REPRESENTAÇÃO FEMININA EM POEMAS DE FLORBELA ESPANCA, MARIA TERESA HORTA E SOPHIA DE MELLO BREYNER ANDRESEN
}

\section{THE FEMALE REPRESENTATION IN POEMS BY FLORBELA ESPANCA, MARIA TERESA HORTA AND SOPHIA DE MELLO BREYNER ANDRESEN}

\author{
Altamir Botoso ${ }^{1}$ \\ João Ricardo Rodrigues ${ }^{2}$
}

\begin{abstract}
Resumo: Neste artigo, estuda-se a representação da figura feminina em três poemas das seguintes escritoras portuguesas: Florbela Espanca, Maria Teresa Horta e Sophia de Mello Breyner Andresen. As mulheres que aparecem em tais poemas não são estereotipadas em boas ou más, mas dotadas de humanidade e capazes de revelar suas intimidades, seus desejos e a disposição de assumir um papel ativo e relevante na sociedade contemporânea.

Palavras-chave: Poesia; Representação Feminina; Literatura Portuguesa; Literatura Comparada.

Abstract: In this article, we study the representation of the female figure in three poems of the following Portuguese writers: Florbela Espanca, Maria Teresa Horta and Sophia de Mello Breyner Andresen. Women who appear in such poems are not stereotyped in good or bad, but endowed with humanity and able to reveal their intimacies, their desires and the willingness to take an active and relevant role in contemporary society.

Keywords: Poetry; Female Representation; Portuguese Literature; Comparative Literature.
\end{abstract}

\section{Introdução}

$\mathrm{Na}$ representação das mulheres em textos canônicos de autores masculinos, de acordo com Lúcia Osana Zolin (2009, p. 226),

é recorrente o fato de as obras literárias [...] representarem a mulher a partir de repetições de estereótipos culturais, como por exemplo, o da mulher sedutora, perigosa e imoral, o da mulher como megera, o da mulher como indefesa e incapaz e, entre outros, o da mulher como anjo capaz de se sacrificar pelos que a cercam. Sendo que à representação da mulher como incapaz e impotente subjaz uma conotação positiva; a independência feminina vislumbrada na megera e na adúltera remete à rejeição e à antipatia.

\footnotetext{
${ }^{1}$ Mestre e Doutor em Letras, área de Teoria Literária e Literatura Comparada pela Universidade Estadual Paulista Júlio de Mesquita Filho, UNESP, campus de Assis-SP, professor do curso de Letras/Espanhol e do Mestrado em Letras da Universidade Estadual de Mato Grosso do Sul - UEMS. 
Dessa forma, as mulheres aparecem retratadas, predominantemente, de duas formas: ou elas são símbolos do mal (sedutoras, megeras, imorais), ou uma encarnação do bem (frágeis, indefesas, submissas). Essa representação é comum tanto no território da prosa quanto no da poesia. Em poemas do período romântico, as mulheres, frequentemente, surgem como seres idealizados, fragilizados, portadores de grande beleza e, em produções poéticas do simbolismo, parnasianismo e modernismo, a figura feminina, muitas vezes, é descrita com qualidades demoníacas, capazes de seduzir e destruir os homens que cruzam o seu caminho.

Vale ressaltar que tais representações devem-se aos escritos de autoria masculina, que sempre procuraram manter a sua supremacia, relegando as mulheres a segundo plano, mantendo-as subjugadas, objetificando-as e considerando-as como um "enfeite", que devia restringir-se às tarefas domésticas e entreter os convidados do marido, como um bibelô, que deveria obedecer cegamente aos padrões e normas estabelecidos pela figura masculina, perpetuando a rigidez e os desmandos do patriarcado ao universo feminino.

Com as mudanças ocorridas ao longo dos séculos $\mathrm{XIX}$ e $\mathrm{XX}$, as mulheres passaram a lutar por seus direitos e a exigir seu espaço no mundo, dentro e fora de seus lares. Nesse sentido, passaram também a escrever obras de ficção, ensaios, poesias, atividades que estavam circunscritas ao mundo dos homens. Dessa maneira,

partindo de suas experiências pessoais, e não mais dos papéis sexuais atribuídos a elas pela ideologia patriarcal, debruçam-se progressivamente sobre a sexualidade, identidade e angústias femininas, bem como sobre outros temas especificamente femininos, como nascimento, maternidade, estupro etc. (ZOLIN, 2009, p. 231).

A partir daí, as mulheres que escreviam e escrevem, seja ficção, ensaio, poesia, passam a conquistar um espaço cada vez mais relevante no mundo contemporâneo e suas produções vem sendo valorizadas, estudadas e apreciadas, tanto quanto as produções realizadas pelo sexo oposto.

Levando em conta os fatos expostos, nosso objetivo é analisar a representação da mulher em três poemas de três autoras portuguesas: Florbela Espanca, Maria Teresa Horta e Sophia de Mello Breyner Andresen.

Inicialmente, apresentamos um panorama que abrange a escritura feminina em solo português, para em seguida, centrarmo-nos nas três autoras selecionadas para este artigo, a fim de desvelar o modo como cada uma delas representa a mulher em suas criações poéticas. 


\section{A literatura de autoria feminina em Portugal}

O estudioso José A. Sabio (1989, p. 181) tece as seguintes ponderações a respeito da literatura feminina em Portugal:

Durante los últimos cuarenta o cuarenta y cinco años, han entrado a formar parte de la vida literaria portuguesa un importantísimo número de escritoras que con su producción artística han venido a enriquecer, de maneira notable, la historia de la ficción y de la poesía de una literatura notoriamente pobre de nombres femeninos. Las obras, especialmente en verso y en prosa, de unas cincuenta escritoras portuguesas contemporáneas constituyen un hecho sin precedente en la literatura del país vecino, perfectamente definido por la abundancia, por la originalidad de su escritura, por la independencia ante las vanguardias literarias y por la inteligencia y delicadeza en ellas desarrolladas. Dedicadas en su inmensa mayoría a la docencia o al periodismo, entre todas ellas mantienen viva en Portugal la voz de la mujer en las letras por medio de la traducción o publicación de obras y de la colaboración en revistas, representando en su conjunto una manifestación cultural de extraordinario valor. [...]

Conforme acertadamente postula o referido estudioso, não se trata de uma literatura feminista, mas de uma literatura feminina,

de fina sensibilidad artística, en la que los grandes temas (el amor, la soledad, la libertad) conviven al lado de aquellos que exploran los mundos de la infancia y de la adolescencia, o presentan la situación de la mujer en la sociedad actual -caso de las Novas Cartas Portuguesas (1972) de Maria Velho da Costa, Maria Teresa Horta y Maria Isabel Berreno-, o analizan la historia más reciente de Portugal centrada en la guerra colonial o en la revolución del 25 de abril $^{3}$. (SABIO, 1989, p. 181).

Complementando as colocações de José A. Sabio, é também importante destacar que

poder-se-ia já pensar em uma série de poetas mulheres em Portugal, anterior mesmo as produções iniciais de Sophia de Mello e das três

\footnotetext{
${ }^{3}$ A data mencionada ficou conhecida também como Revolução dos Cravos e foi "o movimento que derrubou o regime salazarista em Portugal, em 1974, de forma a estabelecer as liberdades democráticas promovendo transformações sociais no país. Após o golpe militar de 1926, foi estabelecida uma ditadura no país. No ano de 1932, Antônio de Oliveira Salazar tornou-se primeiro-ministro das finanças e virtual ditador. Salazar instalou um regime inspirado no fascismo italiano. As liberdades de reunião, de organização e de expressão foram suprimidas com a Constituição de 1933. [...]

No dia 25 de abril de 1974, explode a revolução. [...] A presidência de Portugal foi assumida pelo general António de Spínola. A população saiu às ruas para comemorar o fim da ditadura e distribuiu cravos, a flor nacional, aos soldados rebeldes em forma de agradecimento." http://historiadomundo.uol.com.br/idadecontemporanea/revolucao-dos-cravos.htm. Acesso em: 27 dez. 2016.
} 
Marias, que é notável a qualquer estudo sobre mulheres e as artes no espaço lusófono, pelo que há de invisibilidade e silenciamento, na continuidade da prática patriarcalista da divulgação e crítica, molas da notoriedade de autorias, prática esta que não cessa, mas apenas diminui com o 25 de abril. Assim, deve-se notar que é a repercussão social da dimensão política das vozes das três Marias e o desenrolar artisticamente substancial advindo do episódio do processo jurídico que lhes custou a publicação das Novas Cartas Portuguesas mais o advento de novas vozes em território lusófono que marcam uma espécie de "nova era" [...] das mulheres no terreno da escrita poética [...] em Portugal. (WOLKOFF, 2012, p. 94-95).

As três escritoras denominadas de "Três Marias" são extremamente importantes para o desenvolvimento de uma escrita de poesia de autoria feminina em Portugal, visto que elas romperam o silêncio ao qual estavam relegadas as mulheres escritoras e ao

deslocar-se da reificação silenciada coube inicialmente às três Marias, autoras das Novas Cartas Portuguesas, que abriram campo ao discurso público em torno da sexualidade, do desejo, e da visibilidade do que se supunha "menor", como o sentimento privado e o olhar individual e subjetivo acerca do mundo, pela voz da poesia feminina. (WOLKOFF, 2012, p. 98).

Em conformidade com o que foi exposto, pode-se afirmar que, em Portugal, "é com o impulso das vozes das três Marias que emana o sentido de re-possessão da identidade feminina a partir da palavra poética elocucionada pelas mulheres e que virá com a sucessão de autoras [...] editadas e lidas pós-25 de abril” (WOLKOFF, 2012, p. 98-99). Desse modo, ao falar de si, as mulheres passam a existir pela palavra e apontam para o fato de que elas podem inovar e reposicionar a sua condição feminina na sociedade.

Assim, consequentemente, verifica-se que surgem várias poetisas que abandonam o silêncio e adentram o espaço social e privado para se firmar num universo comandado pelas vozes masculinas e assumem posturas que "antes eram-lhes negadas pública e privadamente, a partir do discurso poético" (WOLKOFF, 2012, p. 95), que lhes permitem revelar peculiaridades próprias da esfera feminina.

Quando tratamos de poesia produzida por mulheres, é válido salientar o aspecto de marginalidade que permeia suas produções e que se configura em duas polaridades que acentuam e intensificam tal aspecto, pois

pensar as identidades femininas e a Poesia leva-nos à questão da marginalidade, pela dupla condição aí presente: mulheres não são iguais aos homens, apesar da constituição portuguesa, que ao assegurar a igualdade sexual nas condições sociais, pressupõe a primeira, ainda que não a veja cumprida e o fato da Poesia ser um gênero menor, aos olhos 
dos leitores-compradores, ou seja, na materialidade das vendas editoriais. [...] (WOLKOFF, 2012, p. 96).

A produção poética de escritoras sofre duplamente a questão da marginalidade, tendo de um lado o fato de os cânones literários serem dominados pelos homens e também o estigma que sofre a poesia, que acaba sendo considerada como um gênero menor e preterida pelos leitores-compradores, o que é comprovado pelos baixos números de vendagem em relação às obras em prosa, por exemplo.

Apesar de enfrentarem problemas como o conservadorismo, a opressão e a censura às manifestações poéticas femininas, as escritoras portuguesas foram, aos poucos, ocupando seu espaço na sociedade e abrindo caminho para que se iniciasse e se conformasse uma "plêiade" de mulheres que se dedicaram ao ofício da escrita em prosa e em verso.

Nesse sentido, há três escritoras que merecem ser mencionadas, face ao papel de pioneiras que assumiram ao adentrar o território da escrita feminina, no qual o domínio e as prerrogativas sempre foram masculinos. As duas primeiras são

Florbela Espanca (1894-1930) e Irene Lisboa (1892-1958), a primeira um grande poeta nos melhores sonetos de amor, e a segunda uma crítica implacável da sociedade e da condição das mulheres nos seus poemas e prosas breves, ficarão como símbolos de antecipação da "nova" mulher. A primeira acabou por se suicidar; a segunda sobreviveu, e contam-se ambas entre as melhores escritoras portuguesas. Outra mulher da mesma geração, Maria Lamas (1893-1983) não é uma grande escritora, mas tornou-se uma das mais respeitadas activistas da oposição ao regime fascista: uma firme esquerdista, que inscreveu importantes estudos sobre as mulheres em Portugal e no mundo, esteve exilada e foi perseguida várias vezes. $[\ldots]^{4}$

Essas escritoras abriram caminho para uma produção ficcional e poética concebida por mulheres, que passaram a tratar de questões que envolvem o universo feminino tais como sua identidade, desejo, erotismo, e a mulher que era objeto, narrada e poetisada por homens, transformou-se em sujeito de suas próprias histórias, enfatizando e pondo em relevo tudo o que se referia a sua interioridade e intimidade no mundo contemporâneo.

No século XX, Portugal ficou marcado pela ditadura de Salazar (1926-1974) e, mesmo com a rigorosa censura a jornais, revistas, teatro e cinema, as mulheres escritoras

4 ESCRITORAS NA LITERATURA PORTUGUESA DO SÉCULO XX. Ensaio. 14 mar. 2012. http://www.lerjorgedesena.letras.ufrj.br/antologias/ensaio/escritoras-na-literatura-portuguesa-do-seculo-xx/. p. 3-4. Acesso em: 27 dez. 2012. 
continuaram se dedicando ao ofício da escrita, assegurando seu espaço e sua competência ao plasmar em poesia ou em prosa, particularidades e dilemas da alma feminina. Desse modo,

chegamos às mulheres que cresceram sob o regime de Salazar, e temos de mencionar [...] Sophia de Mello Breyner Andresen (n. 1919). [...] tornouse activista política nos anos 50, [foi] deputada socialista na Assembleia Nacional. Tão corajosa e tão franca como ela, é Natália Correia (n. 1922), poeta e ficcionista que alinha entre os melhores escritores actuais, que chocou os críticos e o público com a violência e o erotismo das suas últimas obras - é actualmente uma das mais activas jornalistas, escrevendo acerca da Revolução, como muitas outras mulheres têm feito (e a piada em Portugal é que algumas delas têm sido mais "viris" do que os homens, na atitude de desafio de tudo.) Augustina Bessa Luís (n. 1922) e Fernanda Botelho (n. 1926) ou Maria Judite de Carvalho (n. 1928) contamse entre os melhores ficcionistas da actualidade. Salette Tavares (n. 1922) e Ana Hatherly (n. 1929) são importantes poetas que desenvolveram excelente poesia experimental e concreta. Pelo menos três outras mulheres, Maria Teresa Horta (n. 1937), Fiama Hasse Pais Brandão (n. 1938) e Luísa Neto Jorge (n. 1939) são consideradas entre os melhores jovens poetas. ${ }^{5}$

Além dessas escritoras, cabe mencionar outras poetisas que, nascidas no século XX, continuam a escrever, de acordo com José A. Sabio (1989, p. 182-186), como é o caso de Natércia Freire (n. 1920), Natália Nunes (n. 1921), Maria Amália Neto (n. 1928), Maria Alberta Meneres (n. 1930), Maria Gabriela Llansol (n. 1931), Yvette K. Centeno (n. 1940), Olga Gonçalves (n. 1929), Eduarda Dionísio (n. 1946), Wanda Ramos (n. 1948), Fátima Maldonado (n. 1941), dentre outras, que convivem com "escritoras más jóvenesnovísimas, autoras en muchos casos de un único libro y sin una trayectoria literaria aún perfilada" (SABIO, 1989, p. 185), tais como Judith Jorge, Teresa Soares, Teresa Leonor Vale, Guida Fonseca, Laura Gil, Angela Caireles, Matilde Rosa Araújo, Maria de Fátima Borges, Luísa Castro Monteiro, Irene Antunes, Madalena Caixeiro, Clara Pinto Correia.

Os nomes citados acima, a título de ilustração, comprovam a vitalidade e o aumento paulatino da participação das mulheres no desenvolvimento e aprimoramento de uma escrita feminina, seja em prosa, seja em poesia, e que busca alinhavar questões próprias da realidade das mulheres, as quais abandonaram o lugar periférico a que estavam confinadas e assumiram uma posição central na contemporaneidade e tal posicionamento vem se acentuando e se firmando cada dia mais, como uma forma de se

5 ESCRITORAS NA LITERATURA PORTUGUESA DO SÉCULO XX. Ensaio. 14 mar. 2012. http://www.lerjorgedesena.letras.ufrj.br/antologias/ensaio/escritoras-na-literatura-portuguesa-do-seculo-xx/. p. 4. Acesso em: 27 dez. 2012. 
contestar e desestabilizar as balizas do patriarcado, com vistas a uma situação de igualdade e paridade entre os sexos, possibilitando que as autoras possam devassar e expressar suas subjetividades e também semear novas esperanças para o universo feminino que é, em si, plural e merece ser redimensionado, reavaliado e discutido em todas as épocas e, em particular, na nossa atualidade, marcada por contradições, incertezas e fragmentações.

\section{2. "O que tu és...”, de Florbela Espanca}

A escritora Florbela de Alma da Conceição Espanca nasceu em Vila Viçosa (Alentejo), em 8 de dezembro de 1894. Fez seus estudos secundários em Évora. Foi infeliz em seus casamentos, separando-se de seus maridos. Morreu na noite de 7 para oito de dezembro de 1930, devido à ingestão excessiva de barbitúricos (MOISÉS, 2013, p. 356).

Conforme se pode notar, a vida de Florbela Espanca é marcada pelo rompimento de vários tabus da época, pois a poetisa não teve filhos, viveu uma aventura amorosa enquanto casada, divorciou-se por duas vezes e casou-se três. Ana Madalena Fontoura de Oliveira (2013, p. 12), a esse respeito, esclarece-nos que

Seu primeiro casamento se deu em 1913, quando ela contava apenas 19 anos, com o colega de Liceu Alberto de Jesus Silva Moutinho. Em 1921, divorcia-se de Moutinho em 30 de abril e, em 29 de junho do mesmo ano, casa-se com Antonio José Marques Guimarães, alferes de artilharia da Guarda Republicana. Em 1925, porém, divorcia-se de Guimarães em 23 de junho, casando-se, em 15 de outubro deste mesmo ano, com o médico Mário Pereira Lage, com quem permaneceria até sua morte precoce, em 1930.

Em suas produções poéticas, Florbela cantou o amor, o prazer e o erotismo, e é sempre lembrada pelos críticos pela dor e melancolia presentes em sua lírica. O seu primeiro projeto literário foi Trocando olhares, que veio à luz somente na década de oitenta, e que se compõe de poemas escritos entre 1915 e 1916. Sobre essa escritura inicial, é importante assinalar que

A mulher [...] é desenhada como um ser carente, que necessita da luz definidora do homem. Trata-se de um ente sem identidade, imagem de um espaço vazio que aguarda ser preenchido a fim de que possa adquirir sentido. $O$ ambiente de onde emerge tal imagem feminina é o do sonho, nele encontrando a mulher permissão para o interdito, visto que ela habita, 
de fato, um mundo que se acha fora da vida, um universo de exceção, caracterizado por ambiências de cunho noturno.

Florbela esboça, logo de princípio, a acepção de mulher como o de alguém marginal, pertencente à esfera do princípio de prazer, que, mais cedo ou mais tarde, vai entrar em litígio com o princípio da realidade, princípio este que ela concebe como sendo de atribuição masculina. A dor, importante dote feminino na obra de Florbela, nasce desse embate entre os dois princípios antagônicos, e, desde então, se coloca como prerrogativa da mulher e como matéria-prima específica para a sua produção literária. (DAL FARRA, 2012, p. 77).

Verifica-se, nessas tentativas iniciais no campo poético, que Florbela Espanca já coloca a mulher como o centro de suas preocupações, embora ela apareça dependente e atrelada à figura masculina. No entanto, essas tentativas já assinalam para certos temas recorrentes de sua poética como o prazer, a marginalidade da figura feminina e a dor.

Sua obra compõe-se dos seguintes títulos: Livro de mágoas (1919), Livro de Sóror Saudade (1923) e, publicados postumamente, Juvenília (1931), Reliquiae (1931), Charneca em flor (1931) e dois livros de contos: As máscaras do destino e Dominó negro, ambos de 1931.

No Livro de Sóror Saudade, surgem perfis femininos que se materializam em arquétipos como a monja, a princesa, a mulher romântica, todas remetendo a uma simbologia de extrema passividade e abnegação, mas que vão se transformando para dar lugar a uma mulher paganizada, segundo Maria Lúcia Dal Farra (2012, p. 89), quase uma bruxa, que tem prazer em ser marginal e extrair daí o seu orgulho, usando o sofrimento como forma de se libertar.

Pode-se perceber uma evolução na escrita poética de Florbela Espanca, que passa da mulher romântica e dependente do homem para uma criatura quase diabólica, que culmina em uma figura exilada pela dor e o sofrimento. Em Charneca em flor,

assistimos ao desfile de uma plêiade de figurações femininas, que parece comprovar a hipótese de uma personalidade capaz de desdobrar-se ao infinito, como uma dramaturga de si mesma, ou, mais que isso, como um drama cujo palco é a própria mente. A encarnação que lhes dá sustentação parece ser a de uma mulher que se concebe emblemática de sua desgraça feminina exemplar, aquela erigida pela via do sofrimento: a exilada da vida, a perdida, a rejeitada pela sociedade. Mas esse corpo assim tão magoado é que permite a escrita e a poesia, o que a faz poeta em feminino, Poetisa - quando a dor se converte em potência. (DAL FARRA, 2012, p. 93).

Nota-se um desfile de fisionomias femininas na poesia de Espanca, que demonstra um processo contínuo de evolução que procura refletir questões pessoais, que se tornam universais, na medida em que são questões latentes no mundo feminino, no qual a mulher 
se metamorfoseia em ser angelical, diabólico, sofredor, enfim, em inúmeras autorrepresentações que ampliam, reatualizam e redimensionam a figura feminina.

Para este artigo, selecionamos o poema "O que tu és...", que faz parte do volume Livro de Sóror Saudade. Trata-se de um soneto, com rimas do tipo ABBA, ABBA, CDC, ECE:

$$
\text { O Que Tu És... }
$$

És Aquela que tudo te entristece

Irrita e amargura, tudo humilha;

Aquela a quem a Mágoa chamou filha;

A que aos homens e a Deus nada merece.

Aquela que o sol claro entenebrece

A que nem sabe a estrada que ora trilha,

Que nem um lindo amor de maravilha

Sequer deslumbra, e ilumina e aquece!

Mar-Morto sem marés nem ondas largas,

A rastejar no chão como as mendigas,

Todo feito de lágrimas amargas!

És ano que não teve Primavera...

Ah! Não seres como as outras raparigas

Ó Princesa Encantada da Quimera!...

Nesse poema, vemos a descrição de uma mulher que não se enquadra nos moldes sociais da época. Além disso, encontram-se índices que projetam sua insatisfação com tudo que a rodeia, pois sua vida é permeada por uma tristeza insolúvel, devido às condições do universo no qual se encontra inserida.

A figura feminina retratada na obra de Florbela Espanca e, em particular, no poema "O que tu és...", tem marcas da poetisa sentimentalista, erótica, sensual e ansiosa pela liberdade de expressão, que se encontra privilegiada no poema, por meio de um eu-lírico que explora a riqueza lexical da linguagem, os símbolos e a linguagem sugestiva. A riqueza do vocabulário está presente nos verbos "entristece, entrenebrece, deslumbra, ilumina", os quais apontam para uma intensificação da amargura e da infelicidade da figura feminina. 
Mesmo o vocábulo "primavera", que geralmente tem uma conotação positiva, de nascimento ou renascimento, de vida que se inicia, acaba sinalizando para um aspecto negativo, pois a mulher "não teve primavera", significando que ela não conseguiu ser feliz.

Desse modo, no poema fica patente a representação de uma mulher insubmissa, que apresenta também múltiplas faces femininas tais como fraqueza, força, doçura e amargura. Apesar de enfatizar a tristeza da mulher, sobressai a sua força e a sua diferença em relação às demais representantes do sexo feminino e, mesmo com todos os contratempos, ela não se deixa dominar pelos representantes do patriarcado.

\section{3. "Anjos mulheres - IV", de Maria Teresa Horta}

Maria Teresa Horta é considerada uma das poetisas mais importantes da literatura portuguesa atual. Nasceu em Lisboa, em 20 de maio de 1937. Escreveu as seguintes obras: Espelho inicial (1960), Cidadelas submersas (1961), Verão coincidente (1962), Amor habitado (1963), Candelabro (1964), Jardim de inverno (1966), Educação sentimental (1975), Mulheres de abril (1977), Os anjos (1983), Rosa sangrenta (1987), Poesia reunida (2009), As luzes de Leonor (2011), As palavras do corpo (2012), A dama e o unicórnio (2013), Meninas (2014), Ambas as mãos sobre o corpo (2014), Minha senhora de $\operatorname{mim}$ (2015), Anunciações (2016). ${ }^{6}$

A respeito de sua trajetória no universo das letras, a própria escritora manifesta-se nos seguintes termos:

Creio que a minha poesia continua a incomodar, não por ser poesia erótica, mas por ser poesia erótica de uma mulher, que continua a fazer uma abordagem da sexualidade que perturba; e perturba sobretudo os homens, porque não diz aquilo que se convencionou a mulher dizer e até mesmo sentir. Pior do que isso, porque aborda sem o tradicional comedimento ou "recato feminino" o corpo da mulher e a sua ardência, o seu fogo, o seu desejo. Desejo esse de fruição absoluta. (apud MARTINS, 2007, p. 6).

Percebe-se que, apesar da censura e da tentativa de calar a voz da poetisa, esta eleva-se, manifesta-se e grita o seu direito de expressar o seu desejo, a sua sexualidade, o seu corpo encandecido.

Maria Teresa Horta, assim como Espanca, representa a si mesma e a mulher de sua época em suas criações artísticas. Expressa a autorrealização e a libertação feminina

6 As informações contidas neste parágrafo foram extraídas do seguinte site: http://www.portaldaliteratura.com/autores.php?autor=756 Acesso em 24 nov. 2016. 
no momento em que a mulher se desprende dos modelos autoritários de conduta que as limitavam, desvelando, em outras palavras, a insubmissão da figura feminina.

A poetisa tem como características marcantes de sua escrita a sensualidade e impetuosidade que conduzem as potencialidades da linguagem para expressar facetas do universo feminino povoado de beleza, contradições e, acima de tudo, de humanidade, ao retratar a mulher como um ser que se divide em polos antagônicos: céu e terra, liberdade e prisão, anjo e demônio. Em "Anjos Mulheres - IV", que se encontra no livro Os Anjos (1983), a autora escreve sobre o corpo, revelando os dilemas femininos entre a liberdade e a prisão, entre o desejo de liberdade e a presença corporal que a fixa no mundo terreno, expondo a sua face humana e fragilizada através da menstruação.

Portanto, a sua representação oscila entre o divino e o humano, entre o angelical e o terrenal, ressaltando que o ser feminino tangencia e absorve essas contradições, humaniza-se e se desvincula da figura masculina, ao buscar e garantir um espaço só seu. Leiamos o poema:

Anjos Mulheres - IV

As mulheres voam

como os anjos:

Com as suas asas feitas

de cristal de rocha da memória

Disponíveis

para voar

soltas...

Primeiro,

lentamente, uma por uma

Depois,

iguais aos pássaros

fundas...

Nadando,

juntas

Secreta: a rasar o

chão

a rasar a fenda

da lua

no menstruo:

por entre a fenda das pernas 
Às vezes é o aço

que se prende

na luz

A dobrarmos o espaço?

A própria disposição do poema na folha impressa remete à liberdade das sensações, dos sentimentos expressos pelo eu-lírico, que é uma voz feminina que se divide entre o terreno e o celeste, sinalizando um percurso que vai do angelical até atingir a mulher no plano terrestre e a sua dimensão humana.

No poema, as possibilidades de leitura nos remetem a um certo discurso feminista, visto a expressão da independência frente ao gênero masculino, bem como, a um discurso narcisista em relação à própria sexualidade e ao próprio corpo, em favor do bem estar da mulher.

A mulher menstruada, em sua forma idealizada, é aqui representada por anjos. $\mathrm{O}$ eu-lírico vislumbra a condição feminina, sua sexualidade e intimidade, sendo que a problemática relacionada à condição feminina é o traço mais relevante da produção poética de Maria Teresa Horta e que comprova que a figura feminina transita entre contradições, humaniza-se para firmar-se e ocupar seu espaço no mundo contemporâneo.

\section{4. "O mar dos meus olhos", de Sophia de Mello Breyner Andresen}

Nascida no Porto, em 6 de setembro de 1919 e falecida em Lisboa, em 2 de julho de 2004, Sophia de Mello Breyner Andresen publicou contos infantis e para adultos: $A$ menina do mar (1958), A árvore (1985), Contos exemplares (1962), mas a parte mais relevante de sua obra é constituída de obras poéticas (MOISÉS, 2013, p. 462) tais como: Poesia (1944), Dia do mar (1947), Coral (1950), No tempo dividido (1954), Mar novo (1958), O Cristo cigano (1961), Livro sexto (1962), 11 Poemas (1969), Dual (1972), O nome das coisas (1977), Navegações (1983), Ilhas (1989), Musa (1994), Obra poética (2010).

É possível ler alguns poemas de Sophia Andresen como uma revisitação ao mito de Penélope, que pode ser observado numa criação que tem como título o nome dessa divindade mitológica e que, intertextualmente, relaciona o ofício da poetisa e o de Penélope, pelo ato de tecer: "Desfaço durante a noite o meu caminho. / Tudo quanto teci 
não é verdade. / Mas tempo, para ocupar o tempo morto. / E cada dia me afasto e cada noite me aproximo" (ANDRESEN, 2001, p. 226).

Segundo Mariana lanelli (2009, p. 9), no referido poema, busca-se tecer um manto de palavras durante o dia para que ele seja destecido ao anoitecer e, simultaneamente, "exercendo e louvando o ofício da poesia, sob a égide do mito", a escritora portuguesa, "devolve o tempo ao tempo e oferece em seu poema a sedução de um pensamento rítmico. Mais do que uma tarefa acabada, a palavra, ali, renasce, indefinidamente, fio de uma vida que refaz dia após dia o seu caminho".

Além da aproximação às deusas mitológicas, o tecido poético de Andresen assinala outras potencialidades da esfera feminina, conforme assevera Rita Barbosa de Oliveira (2012, p. 120):

[...] O feminino rompe com as ações automatizadas e esvaziadas de significado na vida diária, implica a decisão de tomar uma atitude ética diante do mundo, além de potencializar significados, enriquecendo, assim, com novas imagens a temática da criação e transfiguração do Real.

Em síntese, podemos assinalar que a obra poética de Sophia de Mello Breyner Andresen apresenta uma variedade de imagens recorrentes do universo simbólico feminino (OLIVEIRA, 2012, p. 113), que podem ser aproximadas às deusas mitológicas, mas também às figuras femininas imersas no seu cotidiano, com os seus dilemas e inquietações, materializados numa poesia de grande força expressiva e de uma qualidade inquestionável.

O texto poético escolhido para esta parte de nosso estudo, e que transcrevemos abaixo, faz parte da coletânea intitulada Obra poética (2010).

O mar dos meus olhos

Há mulheres que trazem o mar nos olhos

Não pela cor

Mas pela vastidão da alma

E trazem a poesia nos dedos e nos sorrisos

Ficam para além do tempo

Como se a maré nunca as levasse

Da praia onde foram felizes

Há mulheres que trazem o mar nos olhos

pela grandeza da imensidão da alma

pelo infinito modo como abarcam as coisas e os homens...

Há mulheres que são maré em noites de tardes...

e calma 
O poema transcrito compõe-se de três estrofes, a primeira, com três versos, a segunda, com quatro versos, a terceira, com cinco, e não apresenta rimas, fato que remete às conquistas dos poetas modernistas, que passaram a utilizar em sua composições o verso livre e sem o rigor que caracteriza a poesia mais tradicional.

No referido poema, o mar funciona como uma metáfora da figura feminina, simbolizando a imensidão, a liberdade e a nostalgia de momentos felizes, que são resgatados pela memória, por meio do olhar que recria tais momentos.

$\mathrm{Na}$ primeira e segunda estrofes, surge o verbo "trazer", que religa o passado e o presente, indicando uma mulher que é atuante, tem o poder de eternizar momentos felizes.

A terceira estrofe também apresenta o verbo "trazer", além de elencar elementos que, simbolicamente, remetem à ideia de liberdade ("imensidão", "modo infinito") e as mulheres são comparadas às marés, desvelando um movimento incessante de ir e vir, em calmaria, e o seu modo particular e especial de encarar "as coisas e os homens".

Assim, a mulher se caracteriza como agente positivo, consciente de sua atuação no mundo, bela e capaz de enxergar a realidade e o universo que a cerca e vivenciar experiências felizes, podendo perpetuá-las na sua memória.

\section{Considerações finais}

No poema de Florbela Espanca, "O que tu és...", deparamo-nos com uma representação da figura feminina que está insatisfeita com a realidade que a cerca, pois a mulher está triste, chora, é um "mar morto" e uma "Princesa Encantada da Quimera", ou seja, uma princesa sem castelo, sem príncipe, fadada à infelicidade.

Em Maria Teresa Horta, a mulher que surge em "Anjos Mulheres IV”, destaca-se como uma figura angelical, que é livre, voa como os pássaros, mas, contraditoriamente, é prisioneira da terra e de suas debilidades, como a menstruação, que marca, circunscreve e a acompanha ao longo de sua vida como um estigma de sua fraqueza e, ao mesmo tempo, assinala também a sua sexualidade, marcando a sua diferença em relação ao sexo masculino.

No poema de Sophia de Melo Breyner Andresen, destaca-se uma figura feminina que se assemelha ao mar, fato que nos leva a considerar que a mulher é vista positivamente, pois conquistou o seu espaço no mundo do patriarcado e pode ser livre e feliz. 
Os dois primeiros poemas representam a mulher de uma forma mais negativa, com a exposição de momentos de tristeza, frustrações (em "O que tu és..."), e que apesar de se assemelhar aos anjos e voar como os pássaros, seu ciclo menstrual fixa-a no mundo terreno, deixando patente a sua feminilidade por meio do sangue que sai de seu corpo mensalmente (em "Anjos Mulheres - IV").

O último poema, "O mar de meus olhos", representa a figura feminina positivamente, como um ser que é livre, que pode ir e vir como as marés, numa clara confirmação de que a mulher conseguiu conquistar e firmar-se no mundo contemporâneo.

Diferentemente do que vimos na introdução deste artigo, quando observamos que as mulheres representadas por homens eram estereotipadas em boas ou más, os poemas das escritoras que comentamos aqui revelam uma imagem da mulher que é mais humana (nem somente boa e tampouco somente má), com defeitos e qualidades, mas que seguramente busca e conquista o seu espaço para, a partir dele, vivenciar experiências e vivências que podem ser felizes ou infelizes, mas que buscam assegurar a sua liberdade e a sua capacidade de viver plenamente, sem depender de nada e nem de ninguém.

Assim, ao longo dos três poemas, verificamos uma gradação que principia com uma representação da mulher infeliz e triste, passa por uma mulher que já vislumbra a liberdade, mas ainda conserva-se presa ao mundo terreno, até atingir uma maturidade e uma liberdade que nada e nem ninguém poderá cercear ou anular, no texto poético de Sophia Andresen.

\section{Referências}

ANDRESEN, Sophia de Mello Breyner. Obra poética I. Lisboa: Editorial Caminho, 2001.

DAL FARRA, Maria Lúcia. O errante feminino em Florbela Espanca. ContraCorrente: revista de estudos literários, v. 3, n. 3. Manaus: Universidade do Estado do Amazonas, 2012, p. 75-97.

ESCRITORAS NA LITERATURA PORTUGUESA DO SÉCULO XX. Ensaio. 14 mar. 2012. $<$ http://www.leriorgedesena.letras.ufri.br/antologias/ensaio/escritoras-na-literaturaportuguesa-do-seculo-xx/>. Acesso em: 27 dez. 2012.

IANELLI, Mariana. Por uma poética do feminino. Ângulo, n. 117/118, 2009, p. 08-10.

MARIA TERESA HORTA - BIOGRAFIA. <http://www.portaldaliteratura.com/autores.php?autor=756> Acesso em: 24 nov. 2016. 
MARTINS, Floriano. O corpo aceso da poesia de Maria Teresa Horta. In: HORTA, Maria Teresa. Palavras secretas. São Paulo: Escrituras, 2007.

MOISÉS, Massaud. A literatura portuguesa. 37. ed. rev. e atual. São Paulo: Cultrix, 2013.

OLIVEIRA, Ana Madalena Fontoura de. A interdição do desejo: a poesia erótica feminina e as questões políticas em Portugal no século XX. Idioma, Rio de Janeiro, n. 24, 1. Sem., 2013, p. 6-9.

OLIVEIRA, Rita barbosa de. Sophia: reinvenções poéticas do feminino. ContraCorrente: revista de estudos literários, v. 3, n. 3. Manaus: Universidade do Estado do Amazonas, 2012, p. 113-122.

REVOLUÇÃO DOS CRAVOS. <http://historiadomundo.uol.com.br/idadecontemporanea/revolucao-dos-cravos.htm>. Acesso em: 27 dez. 2016.

SABIO, José A. Literatura femenina en Portugal: una visión panorámica de las escritoras portuguesas contemporáneas. 180 180 186 . <file:///C:/Users/Usu\%C3\%A1rio/Downloads/66878-86640-1-PB\%20(1).pdf>. Acesso em: 27 dez. 2016.

WOLKOFF, Gisele Giandoni. A poesia feminina contemporânea em Portugal. Abriu: Estudos de Textualidade do Brasil, Galicia e Portugal, (1): 93-114, 2012. <http://revistes.ub.edu/index.php/Abriu/issue/view/490>. Acesso em: 27 dez. 2016.

ZOLIN, Lúcia Osana. Crítica feminista. In: BONNICI, Thomas e ZOLIN, Lúcia Osana. Teoria literária: abordagens históricas e tendência contemporâenas. 3. ed. rev. e ampl. Maringá: Eduem, 2009, p. 217-242. 